\title{
PROJETOS DE PESQUISA E A RELAÇÃO COM A METACOGNIC̣ÃO: PERCEPC̣ÕES DE ALUNOS PESQUISADORES SOBRE A PRÓPRIA APRENDIZAGEM ${ }^{1}$
}

\author{
DIÓGENES GEWEHR ${ }^{\text {* }}$ \\ https://orcid.org/0000-0003-4945-9835 \\ ANDREIA APARECIDA GUIMARÃES STROHSCHOEN " * * \\ https://orcid.org/0000-0002-4273-9933 \\ ROGÉRIO JOSÉ SCHUCK $1 * * * *$ \\ https://orcid.org/0000-0001-9275-9193
}

RESUMO: Este artigo buscou analisar a percepção metacognitiva de alunos pesquisadores decorrente da elaboração e desenvolvimento de projetos de pesquisa. Participaram do estudo 133 alunos da Educação Básica e dez professores, abordados em uma feira de ciências de uma universidade comunitária. Os dados foram coletados por meio de questionário Likert e entrevista gravada, analisados mediante método fenomenológico. Ficou evidenciado que a evocação do pensamento metacognitivo se fez presente ao longo do processo da pesquisa, possibilitando aos alunos identificarem seus conhecimentos e se autoavaliarem, e assim obterem ganhos cognitivos. Os resultados apresentados podem levar a uma melhor compreensão do fenômeno estudado, especialmente em termos de compreensão do potencial que possui o ensino e a aprendizagem através da elaboração e desenvolvimento de projetos de pesquisa.

Palavras-chave: Aluno pesquisador. Projeto de pesquisa. Metacognição.

\section{PROYECTOS DE INVESTIGACIÓN Y LA RELACIÓN CON LA METACOGNICIÓN:PERCEPCIONESDEALUMNOSINVESTIGADORES ACERCA DEL PROPIO APRENDIZAJE}

RESUMEN: Este artículo analizó la percepción metacognitiva de alumnos investigadores derivada de la elaboración y del desarrollo de proyectos de investigación. Participaron en el estudio 133 alumnos de la Educación Básica y diez profesores, abordados en una feria de

\footnotetext{
* Doutor em Ensino (UNIVATES), Professor de Biologia no Instituto Federal de Educação, Ciência e Tecnologia Sul-rio-grandense - IFSul. Grupo de pesquisa: Princípio da Investigação e Pedagogia Empreendedora. E-mail:

diogenes.gewehr@universo.univates.br

* * Doutora em Ecologia (UFRGS), Professora dos Programas de Pós graduação: Doutorado e Mestrado em Ensino e Doutorado e Mestrado Profissional em Ensino de Ciências Exatas na Universidade do Vale do Taquari - Univates. Grupo de pesquisa: Princípio da Investigação e Pedagogia Empreendedora. E-mail: aaguim@univates.br

*** Doutor em Filosofia (PUCRS). Professor dos Programas de Pós graduação: Doutorado e

Mestrado em Ensino e Doutorado e Mestrado Profissional em Ensino de Ciências Exatas na Universidade do Vale do Taquari - Univates. Grupo de pesquisa: Princípio da Investigação e Pedagogia Empreendedora. E-mail: rogerios@univates.br
}

I Instituto Federal de Educação, Ciência e Tecnologia Sul-rio-grandense, Venâncio Aires, RS - Brasil. II Universidade do Vale do Taquari, Lajeado, RS - Brasil. 
ciencias de una universidad comunitaria. Se recolectaron los datos por medio del cuestionario Likert y de entrevista grabada, y se los analizaron mediante el método fenomenológico. Se evidenció que la invocación del pensamiento metacognitivo estuvo presente a lo largo del proceso de investigación, posibilitando a los alumnos identificar sus conocimientos y hacer una autoevaluación, y, por lo tanto, obtener beneficios cognitivos. Los resultados presentados pueden sugerir una mejor compresión del fenómeno estudiado, especialmente en relación con la compresión del potencial que tienen la enseñanza y el aprendizaje por medio de la elaboración y del desarrollo de proyectos de investigación.

Palabras clave: Alumno investigador. Proyecto de investigación. Metacognición.

\section{RESEARCH PROJECTS AND THE RELATION WITH METACOGNITION: STUDENT RESEARCHERS PERCEPTIONS ABOUT THEIR OWN LEARNING}

ABSTRACT: This article sought to analyze the metacognitive perception of student researchers resulting from the elaboration and development of research projects. 133 students from Basic Education and ten teachers participated in the study, approached at a science fair at a community university. Data were collected using a Likert questionnaire and recorded interviews, analyzed using a phenomenological method. It was evidenced that the evocation of metacognitive thinking was present throughout the research process, allowing students to identify their knowledge and self-evaluate themselves, and thus obtain cognitive gains. The results presented may lead to a better understanding of the phenomenon studied, especially in terms of understanding the potential that teaching and learning has through the elaboration and development of research projects.

Keywords: Student researcher. Research project. Metacognition. 


\section{INTRODUÇÃO}

A metacognição, em linhas gerais, é a reflexão da própria cognição, a tomada de consciência do sujeito sobre seus conhecimentos, aprendizagens e limitações. Evocar o pensamento metacognitivo é resgatar da memória o que foi estudado, refletindo compreensões e incompreensões, monitorando o próprio pensamento. Neste estudo decorrente de investigações de uma tese de doutorado (GEWEHR, 2019), buscamos adentrar no problema acerca de como se dá a percepção de alunos pesquisadores, por meio de evidências do pensamento metacognitivo, no que tange à aprendizagem decorrente da elaboração e desenvolvimento de projetos de pesquisa.

Por alunos pesquisadores compreenda-se estudantes envolvidos no processo de elaboração e desenvolvimento da pesquisa, mantendo o rigor científico, em conformidade com o projeto de pesquisa previamente elaborado. Nesse sentido, projetos de pesquisa são instrumentos de iniciação à pesquisa norteados por uma metodologia científica, atendendo critérios investigativos específicos que se aproximam, em menor grau de complexidade, de pesquisas realizadas pela comunidade científica.

No presente artigo é abordada a utilização de projetos de pesquisa como estratégia pedagógica e a relação com a metacognição. O estudo teve como principais sujeitos alunos pesquisadores, que participaram de uma feira de ciências em uma universidade comunitária, sendo pré-requisito para a participação o desenvolvimento de projetos de pesquisa. Diferentemente de uma pesquisa comum - aquela em que a maioria dos alunos está habituada a realizar, acessando a internet, abrindo o navegador e copiando os resultados dos primeiros sites (GEWEHR et al., 2016) -, no contexto dos projetos de pesquisa os trabalhos precisam ter um cunho científico, atendendo a características peculiares, como planejamento, sistematização e rigor científico, embasando-se em outros estudos relacionados e necessitando de aprofundamento e discussão sobre o assunto, caracterizando-os como uma pesquisa científica (CHIBENI, 2006; DIAS, EISENBERG, 2017).

Para Gonzatti (2017, p. 7) trabalhar com projetos de pesquisa de modo investigativo, no âmbito da Educação Básica, requer várias rupturas:

[...] de métodos, de teorias e de práticas, de tempos e espaços escolares, bem como incita-nos, estudantes e professores, a deslocamentos de papéis em relação ao modelo hegemônico de escola e de ensino. Definir um problema de pesquisa, formular hipóteses, construir uma estratégia de trabalho, gerar, sistematizar e analisar dados e interpretar resultados, quer de natureza qualitativa ou quantitativa, produzir sínteses, entre outros, são processos que tanto favorecem o desenvolvimento de habilidades cognitivas de nível mais complexo quanto estimulam o espírito colaborativo, solidário e a capacidade de trabalhar e conviver em grupo.

Anterior ao estudo apresentado neste artigo, a estratégia pedagógica projetos de pesquisa foi aplicada por um dos pesquisadores, professor da disciplina de Ciências dos Anos Finais do Ensino Fundamental em duas escolas públicas da região central do Estado do Rio Grande do Sul, sendo possível perceber mudanças de comportamento e atitudes nos alunos que haviam desenvolvido projetos de pesquisa. $\mathrm{O}$ professor pesquisador foi percebendo que à medida 
em que os projetos de pesquisa iam sendo elaborados e executados, os alunos pesquisadores demonstravam-se mais reflexivos e críticos em relação à própria aprendizagem. $\mathrm{Na}$ ocasião de socialização das pesquisas científicas observou ainda que os alunos pesquisadores identificavam suas facilidades e limitações e falavam com propriedade, contextualizando os assuntos de modo diferente do habitual.

Compartilhando a experiência pedagógica com integrantes de um grupo de pesquisa da universidade - relatando as observações diante da elaboração, desenvolvimento e socialização dos projetos de pesquisa, que resultaram em mudanças significativas nos alunos pesquisadores em relação à reflexão e ao autoconhecimento da aprendizagem -, entendemos que haveria a presença de um fenômeno metacognitivo na estratégia de projetos de pesquisa.

A metacognição, trazida com mais detalhes por Rosa (2011, p. 30),

[...] é entendida como a tomada de consciência do sujeito sobre seus conhecimentos, sobre seu modo de pensar, promovendo a regulação de suas ações. No âmbito educacional, atua como estratégia de aprendizagem, permitindo que os estudantes executem ações a partir da identificação de seus conhecimentos. A sua potencialidade para a aprendizagem reside no fato de que promove nos estudantes um pensar sobre seus conhecimentos, oferecendo-lhes condições de controlar a execução de suas ações como se um supervisor monitorasse seus pensamentos. Os estudantes, ao pensarem ativamente sobre o que estão fazendo, são capazes de exercer um controle sobre seus processos mentais e, assim, obter ganhos cognitivos. [...], isso leva à busca pelo conhecimento já existente na estrutura cognitiva, atuando como estímulo à construção dos novos conhecimentos.

Assim, passamos a considerar projetos de pesquisa como espaços potentes para o autoconhecimento da aprendizagem, permitindo com esta estratégia a reflexão crítica do aluno sobre o que sabe e o que ainda precisa aprender - o que geralmente não acontece. Segundo Lizarraga (2010), os alunos têm dificuldades de se autorregularem, não estão acostumados a controlar suas atividades de aprendizagem. Priorizam a execução das tarefas, sem se deterem em planejar como irão conduzi-las, tampouco avaliar seus resultados.

Contudo, de modo que esta consideração não se limitasse ao entendimento do grupo de pesquisa e experiência particular de observação dos próprios alunos, decidimos investigar o fenômeno coletando dados com alunos pesquisadores de outras instituições de ensino, participantes de uma feira de ciências de uma universidade comunitária. Além destes, foram também coletados dados com outros professores orientadores, no sentido de melhor elucidar alguns aspectos que os alunos poderiam ter dificuldade de transparecer em suas respostas, e assim analisar com mais elementos a percepção dos alunos pesquisadores sobre suas aprendizagens com os projetos de pesquisa.

Anterior ao detalhamento da metodologia de coleta e análise dos dados, trazemos autores que discorrem sobre o ensino e a aprendizagem por meio de projetos de pesquisa, onde são abordados os benefícios desta estratégia, que pode ser desenvolvida individual ou em pequenos grupos, de modo coletivo e colaborativo. 


\section{PROJETO DE PESQUISA: ESPACִO PARA EVOCAR O PENSAMENTO METACOGNITIVO}

Em uma perspectiva ativa e participativa, de rupturas de práticas pedagógicas rotineiras, encontra-se o trabalho com projetos de pesquisa (GONZATTI et al., 2017). O trabalho com projetos de pesquisa é uma estratégia pedagógica planejada que promove a construção de conhecimentos mediante o ensino e a aprendizagem baseados na pesquisa. Moran, Masetto e Behrens (2007, p. 79) destacam a importância da pesquisa na educação, diante das mudanças culturais pelas quais passamos:

Aprender a decorar um volume infindável de informações tornou-se tarefa de questionável valor, uma vez que pela produção veloz com que os conhecimentos vêm sendo apresentados e renovados eles tendem a envelhecer rapidamente. A visão ingênua do professor que julga ensinar tudo aos alunos sobre sua disciplina passou a ser impraticável, pois o universo das informações se estendeu e se ampliou. Portanto, mais que apresentar e decorar conteúdos os alunos precisam aprender a acessá-los, a pensar e refletir sobre eles.

Conforme os autores, não é adequado praticar um ensino que priorize a cópia e a memorização. Embora tais atividades tenham seu reconhecimento, é mais coerente ensinar o aluno a buscar e selecionar as informações, para então transformálas em conhecimentos. Para Wekerlin Filho (2001, p. 20) o método de projetos é considerado um meio pelo qual os alunos têm a possibilidade de transcender a receptividade do ensino tradicional, desenvolvendo "[...] independência e responsabilidade, prática social e modos democráticos de comportamento". É o que Vianna (2016) chama de protagonismo estudantil, fazendo referência aos alunos que deixam de ser espectadores e passam a se envolver na busca por soluções para situações problemas, por meio de projetos de pesquisa.

Ao se apropriar da ciência e sentir-se capaz de desenvolver um projeto científico em uma área que seja do seu interesse, os estudantes desenvolvem protagonismo, proatividade, responsabilidade com o mundo em que vivem. Todo jovem que se proponha a resolver um problema real por meio da ciência, redefine seus limites e passa a estar mais capacitado a ser um agente de transformação [...]. Além disso, aprende a se comunicar melhor, trabalhar em equipe, desenvolver disciplina e pensamento crítico, dentre muitos outros benefícios (VIANNA, 2016, p. 17-18).

Esta opinião é compartilhada por Candau e Koff (2015), ao afirmarem que o trabalho com projetos potencializa dinâmicas do aprender a aprender, valoriza o aluno enquanto protagonista e favorece a criatividade e aprendizagens significativas, estimulando-o a pensar sobre o percurso das atividades. Também, a competência como pesquisador, aliada ao desenvolvimento da autonomia e do trabalho, de modo solidário e colaborativo.

Conforme Vianna (2016, p. 32), "o sucesso reside no bom uso do método científico combinado a ideias mais originais do que uma maquete de um vulcão com fumaça". Inovação e originalidade são bem vistos em projetos de pesquisa e estimular a criatividade dos alunos desde cedo é um passo para futuras invenções 
ou descobertas. A autora sugere, ainda, que antes de iniciar qualquer trabalho seja realizado uma ampla pesquisa bibliográfica. Com ela, se "evita que alguém crie algo que já existe ou resolva um problema que já tem solução. É com base no conhecimento prévio que avançamos, e uma pesquisa bibliográfica bem feita evita que o cientista reinvente a roda" (VIANNA, 2016, p. 41).

Para Cabrero e Costa (2015, p. 109) a iniciação científica “é um mecanismo de formação [...], viabiliza despertar talentos e vocações para o campo científico". Ao realizar um projeto de pesquisa o aluno tem a possibilidade de desenvolver um instrumento que o instiga a pensar de modo sistêmico, considerando as etapas da pesquisa norteada por uma metodologia científica. Rausch e Schroeder (2010, p. 321), consideram essa uma prática importante e acessível que as escolas têm condições de proporcionar aos alunos. Do contrário, se não conhecem os procedimentos básicos, quando "chegam à universidade, ficam sem autonomia para desenvolver uma pesquisa. Por isso, a necessidade de inserir a pesquisa em sala de aula desde a Educação Básica, para que os alunos consigam construir conhecimento e elaboração própria”, citam as autoras.

Ao trabalhar com a iniciação científica na Educação Básica, o que se busca não é que os alunos envolvidos no desenvolvimento de um projeto de pesquisa executem investigações científicas a níveis complexos, como aquelas realizadas por pesquisadores da comunidade científica, mas que os alunos pesquisadores se aproximem desta e aprendam a essência de um projeto investigativo (MENDES, 2013). Para Azevedo (2013), incentivar o aluno a observar o mundo a seu redor e a buscar o porquê das coisas, com explicações aprofundadas, é um princípio para despertar a curiosidade e o senso investigativo, o que leva ao desenvolvimento de "habilidades científicas muito importantes e também a própria inteligência, o raciocínio lógico, a capacidade de argumentação, a criticidade” (BORGES, 2011, p. 27), benefícios estes que vão além da pesquisa.

No processo de escrita do projeto de pesquisa o professor deve ser "instância de acompanhamento do aluno", instruir e propor caminhos, valorizar as dúvidas ao invés de apenas cobrar respostas certas, "[...] instigar o aluno a encontrar respostas a problemas que sejam do seu interesse, apontar caminhos, diretrizes, discutir as possibilidades da pesquisa como forma de reconstruir o conhecimento, de fomentar a escrita autoral" (DIAS; EISENBERG, 2017, p. 59). De Maman et al. (2018, p. 95) salienta ainda que, no momento da escrita do projeto, "é importante que haja a preocupação de que se está escrevendo para os outros, ou seja, deve-se apresentar [...] clareza, equilíbrio e unidade possíveis, de modo a revelá-lo ao leitor dentro de um contexto social, histórico, jurídico ou outro", situando o leitor.

Para Anastasiou (2015, p. 16), com base nos estudos de Raths et al. (1977),

Projetar é lançar ideias, intenções, utilizando-se de esquema preliminar, plano, grupo, definição de tarefas, etapas, divisão e integração de trabalho, questão ou problema, identificação das questões norteadoras, definição de abrangência, de fontes, definição de instrumentos de coletas de dados, validação de dados e respostas, etapas e cronograma. Requer assim identificação, comparação, resumo, observação, interpretação, busca de suposições, aplicação de princípios, decisão, imaginação e crítica. 
Como é possível observar, "projetar" é complexo. Conforme Mendes (2013), o projeto de pesquisa precisa ter um foco bem definido, com um tema nem muito amplo, nem muito restrito, logo, nem todos os temas são adequados para serem investigados. Alguns assuntos podem não haver muita bibliografia acessível ou confiável; outros a dimensão ser tão grande que dificulta a abordagem; há ainda a temática particular do aluno, que pode ser difícil para o professor orientar.

Um bom tema é aquele que permite a elaboração de um trabalho relevante, "não é preciso mostrar originalidade, mas [...] a capacidade instrumental, inovadora e correta de apresentar um tema científico" (MENDES, 2013, p. 21, grifo do autor). A prioridade é a prática, a vivência, a realização de "um trabalho de iniciação científica e não um trabalho qualquer sobre o tema que desejar. É bom e desejável que ele [o aluno] aproveite essa oportunidade" (MENDES, 2013, p. 27, grifo do autor). Assim, deixa de ser espectador e inicia uma jornada de pesquisador, passando a produzir conhecimentos. Para Azevedo (2013, p. 5) delimitar o tema é um ponto principal na pesquisa.

Para começar, você não vai saber tudo de uma vez. Não vai, por exemplo, ter condições de investigar todas as doenças parasitárias que acometem todos os animais no mundo, talvez nem no Brasil ou nem mesmo na sua região. Quem sabe, na sua cidade seria mais fácil. Mas seria de todos os animais? Os somente as doenças parasitárias que acometem os seres humanos? Ou ainda as doenças parasitárias que acometem apenas as crianças? Por isso, você precisa delimitar a sua questão a uma dimensão viável.

A autora ainda cita que a pergunta de pesquisa deve permitir chegar a uma resposta possível, embora nem sempre seja a resposta que se tenha tido como hipótese. Além disso, a objetividade da pergunta precisa estar clara e é preciso tomar cuidado para não emitir juízo de valor, utilizando termos como "melhor" ou "pior" (AZEVEDO, 2013).

Quais são os piores parasitas que acometem as crianças da cidade em questão?” Fica difícil responder a essa pergunta, pois o conceito "pior" não pode ser mensurado. A pergunta deveria ser modificada para: "Quais são as parasitoses que causam mais danos à saúde das crianças da cidade analisada"? Com essa mudança, você faz com que a questão passe a ter uma possível resposta, já que os danos à saúde podem ser mensurados (AZEVEDO, 2013, p. 6).

Assim, formular uma pergunta adequadamente é fundamental para não cair em "ciladas" na pesquisa científica, a ponto de não ser capaz de responder com certo nível de segurança determinada questão. "Nossa tendência é divagar e não ser objetivo e preciso na hora de formular nossos questionamentos" (AZEVEDO, 2013, p. 6-7). Ou seja, aprender a fazer perguntas claras e objetivas, delimitadas a uma condição aceitável, sem envolver juízo de valores, é fundamental para desenvolver uma pesquisa científica de qualidade.

Para Rausch e Schroeder (2010), é fundamental que a temática de pesquisa escolhida desperte curiosidade e que haja discussões das informações coletadas com os conhecimentos prévios dos alunos, instigando a argumentação e o pensamento 
crítico e reflexivo. Trata-se de "fazer uma análise rigorosa e, portanto, um exercício de ir além de uma leitura superficial, possibilitando uma construção de novas compreensões e teorias a partir de um conjunto de informações sobre determinados fenômenos" (MORAES, 2003, p. 196). Para Ninin (2008), uma boa alternativa de organização das ideias é por meio do fichamento dos materiais lidos, selecionando trechos para posterior articulação, comparação de aspectos comuns e divergentes e realização de discussão entre diferentes autores acerca de um mesmo assunto.

Wekerlin Filho (2001, p. 21) reforça a importância de os alunos agirem em favor de suas aprendizagens, considerando a elaboração e execução de um projeto de pesquisa como uma tarefa de responsabilidade própria. O autor chama a atenção dos professores para que não tomem os projetos para si, e sim que deixem os alunos se apropriarem, que passem "a ter os projetos como deles, ou o projeto lhes é apresentado e se torna deles. Caso contrário, estará fadado ao fracasso", referindose que, sem interesse e motivação, os alunos não farão as atividades com qualidade.

Agir no sentido da própria aprendizagem tem relação com a metacognição, tida como a consciência de si mesmo, o conhecimento do próprio processo de aprender (BEBER, SILVA, BONFIGLIO, 2014). Os pesquisadores Elosúa e García (1993) inspiradas em Flavell (1981; 1985) - considerado o precursor da metacognição -, a organizam em dois importantes componentes: conbecimento do conbecimento e controle do conhecimento. No primeiro, consideram haver as variáveis pessoa, tarefa e estratégia.

De forma sintetizada, pode-se dizer que a variável pessoa relaciona-se ao conhecimento que os indivíduos têm sobre si mesmos; já a variável tarefa está relacionada às suas demandas e o que ele reconhece sobre elas; por sua vez, a variável estratégia representa o momento em que o sujeito se questiona sobre o que precisa ser feito e quais os caminhos a serem seguidos para atingir o objetivo almejado (ROSA; ROSA, 2016, p. 2-3, grifo nosso).

Já no segundo componente as variáveis são planificação, monitoração e avaliação. Rosa e Rosa (2016, p. 3, grifo nosso) assim as definem:

[...] entende-se por planificaşão o momento em que o sujeito procede à previsão das etapas envolvidas na ação, definindo as estratégias. A operação de monitoração é responsável pelo controle e pela verificação da ação, exercendo uma avaliação constante do realizado frente ao objetivo pretendido. A avaliação, último elemento do processo de evocação do pensamento metacognitivo, possibilita o confronto entre os resultados atingidos e o objetivo estabelecido.

Ao conhecerem estas variáveis os professores podem instigar os alunos a identificarem seus conhecimentos, bem como controlarem suas ações, e assim procederem com determinadas tarefas de modo a obterem maior êxito. Ao evocar seus pensamentos os alunos trazem à memória o que foi estudado, identificando as próprias compreensões e incompreensões, lacunas e aprendizagens (ROSA, 2014; ROSA, 2017).

A seguir apresentamos os caminhos metodológicos deste estudo, que teve como foco de investigação os alunos pesquisadores envolvidos com a elaboração e desenvolvimento de projetos de pesquisa socializados em uma feira de ciências. 


\section{DETALHAMENTO DOS CAMINHOS METODOLÓGICOS}

A pesquisa desenvolvida foi qualitativa (GIL; SILVA, 2015), na qual a descrição seguiu os passos da análise fenomenológica (MOREIRA, 2004), que contou com a participação de 133 alunos da Educação Básica das redes pública e privada, na faixa etária dos 11 aos 18 anos, sendo 100 alunos dos Anos Finais do Ensino Fundamental (EF) e 33 alunos do Ensino Médio (EM), além de dez professores orientadores $(\mathrm{P})$. A adesão ocorreu de modo voluntário, não tendo sido estabelecido um número mínimo ou máximo de participantes. Alunos e professores foram abordados na $7^{a}$ edição de uma feira de ciências, ocorrida em outubro de 2017, em uma universidade comunitária localizada no Vale do Taquari/RS/BRA.

Para as abordagens e coletas junto ao evento, foi solicitada previamente a autorização da Comissão Organizadora, bem como dos responsáveis pelos alunos pesquisadores menores de idade, mediante Termo de Consentimento Livre e Esclarecido (TCLE). Foi solicitada também a assinatura do próprio aluno, em Termo de Assentimento Livre e Esclarecido (TALE), de modo que esse pudesse manifestar sua livre e espontânea vontade em participar da pesquisa. Os professores orientadores participantes também assinaram o TCLE.

Os dados foram coletados com os alunos pesquisadores mediante questionário impresso e com os professores orientadores por meio de entrevista oral individual gravada. O questionário contou com a predominância de questões metacognitivas em escala de níveis (Likert). As questões em escala Likert são uma forma de verificar qual é a opinião de um respondente diante de uma série de afirmações, permitindo captar mais informações do que questionários do tipo "sim" ou "não". Nesta pesquisa os alunos precisaram escolher entre os níveis de frequências: "nunca", "poucas vezes", “às vezes", "muitas vezes” ou "sempre”.

As respostas dos questionários são apresentadas utilizando estatística descritiva e expressas através de gráficos, já as entrevistas foram transcritas. Posteriormente, foram analisadas em um enfoque fenomenológico. Segundo Gil e Silva (2015, p. 102, grifo nosso),

[...] o que se busca alcançar com esse método é a consciência do sujeito mediante a expressão de suas experiências internas. Para a fenomenologia, um objeto é como o sujeito o percebe, devendo, portanto, ser estudado sem interferência de qualquer regra de observação. Assim, tanto um objeto concreto quanto uma sensação, uma recordação ou uma crença, devem ser estudados tal como o são para o espectador.

Neste método de origem filosófica o foco de investigação está naquilo que se manifesta, no fenômeno que surge em razão do contexto, da experiência vivida, da participação do aluno no acontecimento. Algo que muitas vezes faltam palavras para expressar, que nem sempre é possível capturar dentro de conceitos lógicos. Para os autores, a fenomenologia permite "investigar aspectos da existência para os quais os procedimentos tradicionais das ciências humanas não se mostram suficientes. Sobretudo para a investigação da experiência vivida no mundo do dia a dia das pessoas" (GIL; SILVA, 2015, p. 102). 
Moreira (2004, p. 117), cita que o método fenomenológico faz parte de uma grande corrente metodológica, e assim “[...] embora se possa dizer que existe um só método fenomenológico, ele admite muitas variantes”. Dentre elas está o método fenomenológico de Giorgi (1985). Nesse método realiza-se uma leitura geral (sentido do todo) dos discursos dos participantes e destacam-se evidências das falas, fragmentando as informações relevantes e organizando-as em unidades de significado. Captada as essências destas unidades interpretam-se os discursos, procurando compreender os fenômenos manifestados. Por fim, é produzida uma sintese do todo, evidenciando as essências dos fenômenos (HARRES, 1997; MOREIRA, 2004; ANDRADE, HOLANDA, 2010).

Apresentada a metodologia, a seguir descrevemos os achados deste estudo, discutindo os resultados com a literatura. Salienta-se que os questionários dos alunos pesquisadores foram analisados separadamente por nível de conhecimento, EF e EM, não com o intuito comparativo, mas em razão da diferente caminhada instrucional de cada nível.

\section{RESULTADOS E DISCUSSÕES EMERGENTES}

Os alunos pesquisadores participantes deste estudo responderam a uma série de questões metacognitivas. Apresenta-se um recorte das questões discutidas, visando analisar a percepção dos alunos pesquisadores quanto a aprendizagem decorrente da elaboração e desenvolvimento de projetos de pesquisa. As questões metacognitivas selecionadas, representadas pela letra Q e um numeral, são apresentadas no Quadro 1.

Quadro 1. Bloco de questões metacognitivas

\begin{tabular}{|c|l|}
\hline Q1 & Pensei bastante para organizar as ideias e elaborar meu projeto de pesquisa. \\
\hline Q4 & Quando não entendia algo que lia, retornava ao início para tentar entender. \\
\hline Q5 & Parava para pensar se eu estava realmente no caminho certo da pesquisa. \\
\hline Q6 & Conseguia reconhecer minhas facilidades, dificuldades e limitações. \\
\hline Q8 & Analisar os dados da pesquisa exigiu-me concentração e reflexão. \\
\hline Q9 & Minha escrita evoluiu, está mais fácil ordenar as ideias e expressar o que quero dizer. \\
\hline
\end{tabular}

Fonte: 0 autor (2017).

Estas questões deram origem a gráficos expressos em porcentagem, referente as respostas dos 100 alunos do EF (GRÁFICO 1) e 33 alunos do EM (GRÁFICO 2), sobre as percepções quanto ao processo envolvido na elaboração e desenvolvimento de seus projetos de pesquisa. A intenção foi que os alunos refletissem desde o processo inicial até o desenvolvimento final dos projetos, os quais resultaram na pesquisa científica em si. 
Gráfico 1.Percepção, em porcentagem, de 100 alunos do Ensino Fundamental sobre a elaboração e desenvolvimento de sua pesquisa científica

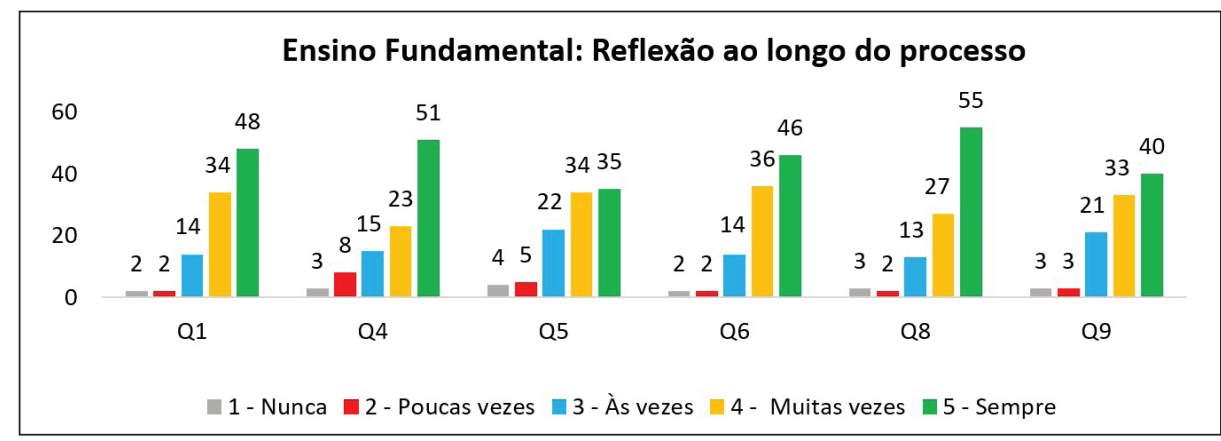

Fonte: 0 autor (2018).

Gráfico 2. Percepção, em porcentagem, de 33 alunos do Ensino Médio sobre a elaboração e desenvolvimento de sua pesquisa científica

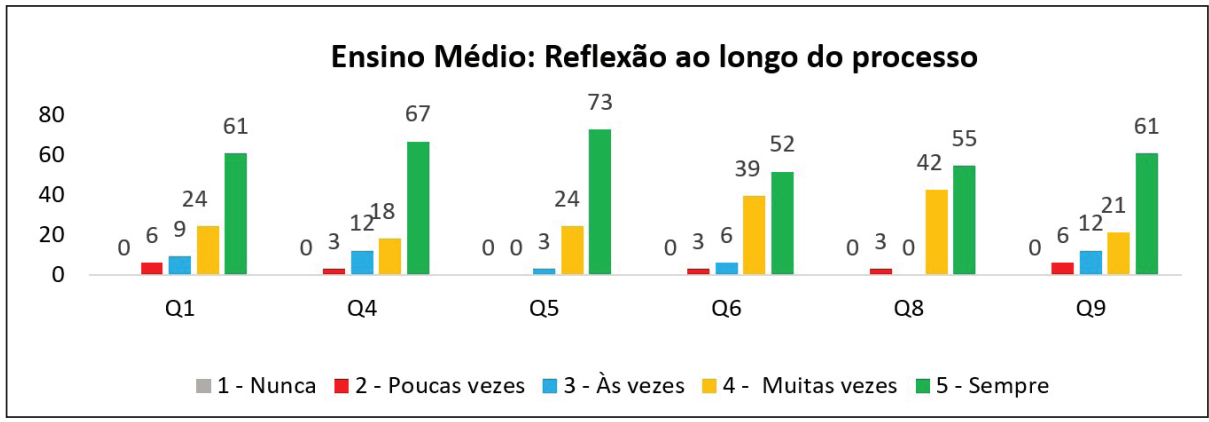

Fonte: 0 autor (2018).

Analisando os gráficos, observa-se que na Q1 82\% (82 alunos) do EF e 85\% (28 alunos) do EM afirmaram pensar bastante para organizar as ideias e planejar a pesquisa, selecionando como respostas as alternativas "sempre" ou "muitas vezes", demonstrando um alto índice de envolvimento com o projeto de pesquisa. Este pensar sobre o projeto potencializa o aprender a aprender, ao se avaliar o estado atual do projeto e vislumbrar aonde se quer chegar (DEMO, 2011; CANDAU, KOFF, 2015). Para Vianna (2016), com a metodologia de projetos os alunos passam a ser protagonistas, envolvendo-se em situações problemas, deixando de lado a condição de espectador do ensino tradicional.

As demais questões deste recorte, Q4 a Q8, que abordavam se os alunos pesquisadores paravam para pensar, analisar e retomar seus pensamentos, na medida que desenvolviam suas pesquisas e discutiam os resultados, tiveram como resposta predominante a frequência "sempre" seguida de "muitas vezes", em um total de 74\% (74 alunos) no EF e 85\% (28 alunos) no EM, referente a questão Q4; 69\% (69 alunos) no EF e 97\% (32 alunos) no EM, no tocante da Q5; 82\% (82 alunos) no EF e 91\% (30 alunos) no EM, concernente a Q6; 82\% (82 alunos) no EF e 97\% (32 alunos) no $\mathrm{EM}$, relativo a Q8. Tais respostas sugerem evidências de alta atividade do pensamento 
metacognitivo, relacionáveis aos componentes metacognitivos "conhecimento do conhecimento" e "controle do conhecimento", trazidos por Elosúa e García (1993).

Assim, ao perceber que não entendeu determinado conteúdo e retornar para tentar entender (Q4), refletir se realmente está em um caminho que vem trazendo resultados (Q5), reconhecer os aspectos que domina e aqueles que ainda precisam de mais atenção (Q6) e analisar todo o conjunto da pesquisa com atenção (Q8), o aluno pesquisador está agindo de acordo com as variáveis dos componentes metacognitivos. Ou seja, ele identifica o próprio conhecimento (pessoa), relaciona com suas necessidades (tarefa), estabelece o que precisa ser feito e como (estratégia), prevê as etapas de sua ação (planificação), controla e verifica o que foi realizado e o que ainda precisa executar (monitoração), confere os resultados alcançados e os objetivos que se propôs a resolver (avaliação) (ROSA; ROSA, 2016).

Para Locatelli (2017, p. 18),

o monitoramento ativo e a autorregulação são elementos fundamentais para se identificar inconsistências no ensino-aprendizagem de algo e tornar possível a retomada do processo, com redirecionamentos rumo ao objetivo de uma aprendizagem eficaz e adequada.

Conforme afirmaram, os alunos pesquisadores demonstraram a capacidade de pensar sobre seus conhecimentos e identificar suas compreensões e incompreensões, reconhecendo pontos que necessitavam ser mais bem explorados. Desse modo, controlando suas ações e identificando desarmonias, no sentido de sanar dificuldades, obtém ganhos cognitivos que os auxiliam a atingir uma aprendizagem eficaz (ROSA, 2011; LOCATELLI, 2017). Este discernimento por parte expressiva dos alunos é um aspecto positivo, contudo, como pontuado no trabalho de Cavalcanti e Ribeiro (2016), em estudo realizado com estudantes de uma mesma faixa etária relacionado a interpretação e compreensão da aprendizagem, costuma necessitar de estímulo do docente para ser efetivado.

[A] capacidade de avaliar a própria compreensão ainda costuma ser um problema para muitos alunos, seja porque possuem baixa capacidade em monitorarem sua compreensão, motivo que os levam a não detectar falhas, seja porque as detectam, mas desconhecem o modo de saná-las, sendo, portanto, necessário ensinar a esses jovens estratégias que possam favorecê-los [...] (CAVALCANTI; RIBEIRO, 2016, p. 31).

Em relação a este hábito de refletir a própria aprendizagem, os professores orientadores foram questionados 'se os alunos paravam para pensar e refletir sobre o processo da pesquisa’ e assim substanciar vestígios de atividade metacognitiva. Após identificar evidências, na análise fenomenológica do sentido do todo, foi possível constituir quatro unidades de significado a partir das essências de suas falas: "Depende de aluno para aluno" (P1; P3; P7); "Paravam para refletir" (P2; P10); "Não paravam para refletir" (P4) e "A reflexão vem com o tempo" (P5; P6; P8; P9). Como as três primeiras unidades são mais compreensíveis, nos detemos nos fenômenos expressos na última unidade, utilizando duas falas para discutir. Vejamos: 
"Nas turmas de $6^{a} / 7^{a}$ série começa essa transição do pensamento, eles ainda estão muito focados, 'Tá, eu tenho que fazer isso, depois aquilo', ficam no processo meio que de escada que parece que uma etapa tem que seguir muito bem a outra. Os alunos já de 8a/9a em diante começam a se dar conta de que dá pra ir e voltar, e às vežes até analisar: 'Olha, meu objetivo não está adequado com o que estou fazendo, então eu tenho que ou mudar o meu objetivo do trabalho ou mudar o método que estou utilizando, que não está me levando para onde preciso ir, não estou conseguindo responder à pergunta problema'. Essa reflexão é mais visivel a partir da $8^{a} / 9^{a}$ série, enquanto que na $6^{a} / 7^{a}$ têm muita dificuldade ainda de [...] compreender o conjunto todo (P5)".

"Eu acho que uma caminhada de experiência propõe isso a eles. [...] A primeira pesquisa não muito, acho que em tudo quando eles trabalham no primeiro momento, de pesquisa mais formal, eles não se dão conta. Quando eles vêm para uma feira de ciências e ai eles veem a caminhada dos demais, o que poderiam ter feito, eles começam a autoavaliação, ai a gente percebe que na próxima vez eles vêm melhor, e na próxima vêm melhor. Eles começam a perceber isso porque em determinados momentos eles mesmo quando são questionados pelos avaliadores dizem: 'Bah, mas isso a gente não se preparou, não se deu conta, isso a gente não viu'. [...] Então, assim, eles já têm noção que eles podem ir além da pesquisa deles, mas é uma caminhada (P6)".

Tanto P5 quanto P6 deixam claro em suas falas que a experiência vai transformando os alunos. $\mathrm{Na}$ fala de $\mathrm{P} 5$ os alunos estão habituados a um processo linear, em que uma fase da pesquisa depende da outra, não vendo possibilidade de retroceder ou pular alguns degraus. É preciso avançar, seguir em frente, pois é assim que entendem a pesquisa, uma sequência de passos fixos a serem seguidos. Percepção semelhante foi relatada há duas décadas atrás por Moreira e Ostermann (1993, p. 113), ao analisarem livros didáticos que abordavam o método científico. Segundo os autores, os livros didáticos analisados pareciam " [...] transmitir ao aluno a ideia de que o método científico é uma sequência rígida, lógica, de passos [...] reforçar ou gerar várias concepções errôneas sobre ciências". O mesmo é perceptível no depoimento de $\mathrm{P} 6$, que afirma que os alunos em sua primeira pesquisa percorrem um rol de formalidades, sem compreenderem a totalidade do processo.

Após participarem de uma feira de ciências, como posto por P6, ou mesmo evoluírem em seus estudos, como dito por P5, os alunos experienciam outros meios de viver a pesquisa. Entendem a necessidade de elaborar seus projetos seguindo passos, avançando degraus, mas compreendem que é possível 'pisar com o pé direito' e depois com o esquerdo, ou ao contrário, ou ainda utilizar os dois pés. Igualmente, podem andar dois degraus, retroceder um, avançar mais alguns. A vivência da experiência permite melhores compreensões. Nas palavras de Gadamer (2007, p. 462), "quando se fez uma experiência, isso significa que a possuímos. A partir desse momento, o que antes era inesperado passa a ser previsto". O desconhecido passa a ter forma, ser lembrança, permite novas possibilidades. A pesquisa não se limita mais a sucessão início, meio e fim, agora se expandiu, pode ser horizonte.

Como pode ser observado, os professores orientadores entrevistados também afirmam que os alunos pesquisadores desenvolvem a capacidade de se autoconhecerem e se autorregularem, inerentes da metacognição vivenciada pela experiência nos espaços dos projetos de pesquisa e feiras de ciências. 
Resultado semelhante é trazido no estudo de Zuliani e Ângelo (1999, p. 1), que avaliaram a aplicabilidade do método investigativo envolvendo projetos de pesquisa, em que a estratégia metacognitiva "proporcionou aos alunos um efetivo incremento na aprendizagem dos assuntos abordados nos projetos". Conforme os autores, os alunos passaram a reconhecer e avaliar suas ideias ativamente, "sendo capazes inclusive de alterar metodologias, perceber os próprios erros e buscar alternativas para a solução dos mesmos" (ZULIANI; ÂNGELO, 1999, p. 9) assumindo o controle da própria aprendizagem.

Em continuidade da análise, a Q9 faz referência à organização do conteúdo contido na pesquisa, necessitando o aluno refletir e avaliar como percebeu sua escrita ao final do processo, em comparação com seu planejamento, se observou evolução e se conseguiu expressar o que queria dizer.

Aproximadamente três quartos, 73\% (73 alunos) do EF, quando somadas suas respostas "sempre" ou "muitas vezes", consideraram que sua escrita evoluiu, sendo possível se expressar com mais facilidade. Novamente este número é maior no EM, em que $82 \%$ (27 alunos) declararam perceberem-se desta forma, indicando o desenvolvimento dos alunos no transcorrer dos anos escolares.

Para Lima (2011), uma boa comunicação em uma feira de ciências é fundamental, pois atinge públicos de diversas faixas etárias, o que exige uma redação precisa e objetiva de modo a ser compreensível por todos. Esta autora destaca em seu estudo que as pesquisas científicas oportunizam um estilo redacional específico aos alunos pesquisadores, impulsionando suas competências comunicativas, o que também pode ser observado em nossos resultados.

Procurando mais bem entender a relação de projetos de pesquisa desenvolvidos e apresentados em feiras de ciências com a aprendizagem, perguntamos aos professores orientadores sobre como percebiam a aprendizagem dos alunos ao longo do processo da pesquisa e na ocasião de socialização na feira de ciências. Desta análise emanaram duas unidades de significado: "Contribuiu para a autonomia" (P1; P8) e "Evoluíram com o passar do tempo" (P2; P3; P4; P5; P6; P7; P9; P10). Destacamos algumas falas:

"Acho bem válido, mesmo com todas as dificuldades, para eles terem mais autonomia, procurarem $e$ buscarem as coisas. Eles se acomodam muito e querem tudo pronto, que o professor chegue em sala de aula, passe as informações e deu, [...] então incentivamos estes trabalhos para se envolveram mais (P1)".

"Estes que buscam a participação em feiras ocorre uma maior preocupação com o apropriamento do conteúdo, se apropriar da informação. Tanto que a ideia que trabalhamos é que não podes decorar o trabalho, na verdade o trabalho que tem que partir de ti para o papel, e não do papel para ti, então, sim, eles têm dado nesse sentido reflexos de que bá uma melhora gradativa na aprendizagem deles. Inclusive eles conseguem dar conta de fazer o que é o mais difícil na sala de aula, analisar as informações que o professor trą. Estão comparando as informações, acompanhando o raciocínio do professor e não simplesmente recebendo as informações prontas, o que era um hábito muito comum na escola e que a gente vem mudando. É preciso estabelecer relação, não é só receber o conteúdo, ele precisa conversar comigo (P5)".

"É fácil perceber que o aluno está evoluindo. Tenho aqui uma experiência de um grupo que vem pelo 
$3^{\circ}$ ano consecutivo, é muito mais tranquilo a organização. Não precisei me estressar com prazos: Pode deixar que a gente já sabe o que tem que fazer', 'A gente já está com isso pronto', a construcão de gráficos, tudo já calculado. Sabe, quando a gente vai solicitar [...] 'A qui prof.já encontramos o gráfico, está aqui a porcentagem, e tal', [...] os dados já vem pronto nessa evolução (P6)".

Diante das respostas, é possível observar que, para P1, as vivências dos alunos com a pesquisa oportunizaram autonomia, possibilitando o engajamento destes nas atividades investigativas. Realidade, esta, que não é comum no dia a dia da referida sala de aula, pelo que se percebe na fala de P1, em que os alunos estão habituados à passividade e receptividade de conteúdos, o que remete ao ensino transmissivo discutido por Moran, Masetto e Behrens (2007).

Neste ensino, esses autores posicionam os professores como os detentores do saber, desenvolvendo com seus alunos atividades basicamente estruturadas na sistemática de cópia e memorização, transmitindo conteúdo do quadro ou livro didático para seus cadernos, tais quais ali estavam, com todas as vírgulas e parágrafos presentes. Contudo, como relatado por P1, este cenário é modificado com a inserção da pesquisa na prática pedagógica, colocando o aluno como sujeito atuante. Cabe a ele aprender a aprender, saindo da condição de um aluno que copia, para um aluno que pesquisa, ressignificando conteúdos com autonomia (NININ, 2008; DEMO, 2011).

Tanto a fala de P5 quanto a de P6 situam-se em outro cenário ao dito por P1. Embora P1 informe que a pesquisa favoreça a autonomia, reconhecendo sua importância na formação do aluno, deixa transparecer que ela é uma situação isolada na sala de aula. Já P5 e P6 residem numa condição diferente, na qual a pesquisa está conjugada a suas práticas rotineiras com os alunos, os quais vão progredindo com o tempo.

Ainda que estas informações não estejam totalmente explícitas nos recortes das falas, o fenômeno vivenciado com estes professores revelou essas faces. Foi possível perceber, nestes e nos demais professores entrevistados, quando a pesquisa era uma estratégia pedagógica presente enquanto processo rotineiro e quando era uma atividade isolada voltada à feira de ciências. Independentemente da situação, o que todos reconhecem é que desenvolver pesquisa e socializar este conhecimento é uma estratégia potente para favorecer o desenvolvimento intelectual e a autonomia dos alunos.

\section{CONSIDERAÇÕES FINAIS}

Tendo como base os dados coletados com os alunos pesquisadores e professores orientadores sobre as atividades desenvolvidas com projetos de pesquisa, em consonância com os preceitos da metacognição e do método fenomenológico, este artigo procurou analisar a percepção metacognitiva de alunos pesquisadores no que tange à aprendizagem decorrente da elaboração e desenvolvimento de projetos de pesquisa.

A análise dos resultados evidenciou que a evocação do pensamento metacognitivo se fez presente ao longo da elaboração e desenvolvimento dos projetos de pesquisa, possibilitando aos alunos pesquisadores identificarem seus conhecimentos e se autoavaliarem, reconhecendo facilidades e dificuldades, e assim 
estabelecerem ações de melhorias em suas aprendizagens, pensando em alternativas para mudar aquilo que não estava favorável em suas pesquisas científicas.

Conforme argumentou Locatelli (2017), o monitoramento ativo e a autorregulação são essenciais para a identificação de inconsistências na aprendizagem, permitindo a retomada do processo. Este aspecto também é defendido por Carvalho (2007, p. 62), que afirma que com a pesquisa os alunos relacionam suas informações "aparentemente diversas e distantes [...] gerando novas conexões em suas mentes", possibilitando retomarem informações e (re)construírem seus conhecimentos.

Diante disso, as percepções iniciais do professor de Ciências, acerca das mudanças de comportamento e atitudes de seus alunos envolvidos com os projetos de pesquisa, puderam ser constatadas além da própria experiência pessoal de observação. Os resultados apresentados demonstram que a estratégia pedagógica de ensino com projetos de pesquisa favoreceu os alunos além da prática educativa no ensino de Ciências. Os alunos pesquisadores desenvolveram atitudes protagonistas, deixando a condição de espectadores do ensino tradicional e envolvendo-se em situações-problemas reais, ampliando aprendizagens além da sala de aula. Aos professores sugere-se o contínuo incentivo e disposição na condução dos alunos pelos caminhos da pesquisa, atuando como mediadores nas descobertas e redescobertas que surgirão ao longo do processo da pesquisa.

Desse modo, consideramos que nosso problema de pesquisa foi respondido, pois ao refletirem criticamente sobre seus projetos de pesquisa, avaliando aspectos positivos e a melhorar, os alunos pesquisadores evocam um pensamento metacognitivo que os conduzem à uma autonomia gradativa. Frente a estes reconhecimentos estarão a obter ganhos cognitivos, pois o exercício metacognitivo permitiu perceber que tal ação pode ser aplicada em diversas situações, extrapolando os limites inerentes aos projetos de pesquisa.

As limitações desta pesquisa se dão no sentido de que o processo metacognitivo é congruente a cada pessoa, à autopercepção e à autoavaliação. Sendo assim, qualquer generalização, por menor que seja, não se aplica como preceito. O estudo foi de grande valia, por contribuir para que os alunos pesquisadores, ao refletirem o desenvolvimento de seus projetos de pesquisa, pudessem voltar o pensamento sobre a própria aprendizagem. Nesse sentido, os resultados aqui apresentados podem levar a uma melhor compreensão do fenômeno estudado, permitindo estabelecer relações com a própria situação existencial, especialmente em termos de compreensão do potencial que possui o ensino e a aprendizagem através da elaboração e desenvolvimento de projetos de pesquisa.

\section{REFERÊNCIAS}

ANASTASIOU, L. G. C. Ensinar, aprender, apreender e processos de ensinagem. 2015. Disponível em: <http://www.cfn.org.br/wp-content/uploads/2015/09/Oficina-3-Desafios-dotrabalho-docente-na-avaliacao-processual-Conteudo-utilizado-1.pdf> Acesso em: 10 ago. 2017.

ANDRADE, C. C; HOLANDA, A. F. Apontamentos sobre pesquisa qualitativa e pesquisa empíricofenomenológica. Estudos de Psicologia, v. 27, n. 2, p. 259-268, abr./jun., 2010. 
AZEVEDO, C. B. Metodologia científica ao alcance de todos. $3^{a}$ ed. Barueri, SP: Manole, 2013.

BEBER, B.; SILVA, E.; BONFIGLIO, S. U. Metacognição como processo de aprendizagem. Rev. Psicopedagogia, v. 31, n. 95, p. 144-151, 2014.

BORGES, R. M. R. Iniciação científica nas séries iniciais. In: PAVÃO, Antonio Carlos; FREITAS, Denise de (org.). Quanta ciência há no ensino de ciências. São Carlos: EdUFSCar, 2011. p. 25-33.

CABRERO, R. C.; COSTA, M. P. R. Iniciação científica, bolsa de iniciação científica e grupos de pesquisa. In: MASSI, L.; QUEIROZ, S. L. (org.). Iniciação científica: aspectos históricos, organizacionais e formativos da atividade no ensino superior brasileiro. São Paulo: Editora UNESP, 2015. p. 109-129.

CANDAU, V. M. F.; KOFF, A. M. N. S. A didática hoje: reinventando caminhos. Educação \& Realidade, Porto Alegre, v. 40, n. 2, p. 329-348, abr./jun. 2015.

CARVALHO, F. A. H. Reaprender a aprender: a pesquisa como alternativa metacognitiva. 2007, 150 f. Tese (Doutorado em Educação) - Faculdade de Educação, PUCRS, Porto Alegre, 2007.

CAVAlCANTE, V. M. P.; RIBEIRO, M. C. M. A. Contribuições do ensino de estratégias metacognitivas de leitura no ensino fundamental. Revista Prolíngua, v. 11, n. 1, p. 27-39, 2016.

CHIBENI, S. S. Algumas observações sobre o "método científico". Notas de aula. 2006. Disponível em: <http://www.unicamp.br/ chibeni/textosdidaticos/metodocientifico.pdf> Acesso em: 13 abr. 2017.

DE MAMAN, A. S. . Projeto de Pesquisa: Oficina da Feira de Ciências Univates. Cap. 7. In: GONZATTI, S. E. M.; HERBER, J. (org.). Articulações Possíveis entre ensino e extensão: experiências pedagógicas do projeto Redes Interdisciplinares. Lajeado: Ed. Univates, 2018.

DEMO, P. Educar pela pesquisa. $9^{a}$ ed. Campinas: Autores Associados, 2011.

DIAS, W. T.; EISENBERG, Z. W. Há espaço para a construção autoral nos trabalhos de pesquisa escolar. 2017. 260 p. Tese (Doutorado em Educação) - Pontifícia Universidade Católica do Rio de Janeiro, Rio de Janeiro, 2017.

ELOSÚA, M. R.; GARCÍA, E. Estrategias para enseñar y aprender a pensar. Madrid: Ediciones Narcea, 1993, cap. 1 a 4. Disponível em: <http://www.cucs.udg.mx/avisos/Martha_Pacheco/ Software $\% 20 \mathrm{e} \% 20$ hipertexto/Antologia_Electronica_pa121/ELOSUA.PDF> Acesso em: 08 ago. 2017.

FLAVELL J. H. Cognitive Development. New York, Prentice-Hall, 1985.

FLAVELL, J. H. "Metacognition and cognitive monitoring: A new area of cognitive-developmental inquiry", en PARKE, H. (De.) Contemporary Readings in Child Psychology. New York, Mc. Graw Hill, 1981.

GADAMER, H. G. Verdade e Método I: Traços fundamentais da hermenêutica filosófica. Petrópolis: Vozes, 2007.

GEWEHR, D. Projetos de Pesquisa e Feiras de Ciências como espaços de metacognição. 2019. 184 p. Tese (Doutorado em Ensino) - Universidade do Vale do Taquari - Univates, Lajeado, 14 jan. 2019. Disponível em: <http://hdl.handle.net/10737/2762>.

GEWEHR, D. et al. Metodologias ativas de ensino e de aprendizagem: uma abordagem de iniciação à pesquisa. Ensino e Pesquisa: Revista Multidisciplinar de Licenciatura e Formação Docente, v. 14. n. 1 p. 225-246, jan./jun. 2016. 
GIL, A. C.; SILVA, S. P. M. O método fenomenológico na pesquisa sobre empreendedorismo no Brasil. Revista de Ciências da Administração, v. 17, n. 41, p. 99-113, 2015.

GIORGI, A. Phenomenology and Psychological Research. Pittsburgh: Duquesne University Press, 1985.

GONZATTI, S. E. M. Apresentação. In: MAGEDANZ, A. et al. (org.). $6^{\text {a }}$ FEIRA DE CIÊNCIAS UNIVATES: DESCOBRINDO TALENTOS PARA A PESQUISA, 2016, Lajeado, RS. Anais... Lajeado: Univates, 2017. E-book. Disponível em: <https://www.univates.br/evento/feira-deciencias/anais>. Acesso em: $18 \mathrm{dez} .2017$.

GONZATTI, S. E. M. et al. Análise de objetos de estudo escolares em uma Feira de Ciências: (possíveis) transgressões metodológicas e epistemológicas. In: XI ENCONTRO NACIONAL DE PESQUISA EM EDUCAÇÃO EM CIÊNCIAS - XI ENPEC, Florianópolis, 2017. Anais... Florianópolis: UFSC, 2017.

HARRES, J. S. O ato de brincar na Educação Infantil: implicações no processo escolar. 1997.183 f. Dissertação (Mestrado em Educação) - Pontifícia Universidade Católica do Rio Grande do Sul, Porto Alegre, 1997.

LIMA, M. E. C. Feiras de ciências: o prazer de produzir e comunicar. Cap. 3. In: PAVÃO, A. C.; FREITAS, D. (org.). Quanta ciência há no ensino de ciências. São Carlos: EdUFSCar, p. 195-205. 2011.

LIZARRAGA, M. L. S. A. Competencias cognitivas en educación superior. Madrid, Espanha: Narcea S. A. de Ediciones, 2010.

LOCATELLI, S. W. A metacognição e o ensino de Ciências: um breve panorama. In: FALEIRO, W.; ASSIS, M. P. (org.). Ciências da Natureza e Formação de Professores: entre desafios e perspectivas apresentados no CECIFOP 2017. Jundiaí, SP: Paco Editorial, 2017.

MENDES, F. R. Iniciação científica para jovens pesquisadores. $2^{\mathrm{a}}$ ed. Porto Alegre: Autonomia, 2013.

MORAES, R. Uma Tempestade de Luz. A compreensão possibilitada pela Análise Textual Discursiva. Ciência \& Educação, Porto Alegre, v. 9, n. 2, p. 191-211, 2003.

MORAN, J. M.; MASETTO, M. T.; BEHRENS, M. A. Novas tecnologias e mediação pedagógica. $13^{\mathrm{a}}$ ed. Campinas, SP: Papirus, 2007.

MOREIRA, D. A. O método fenomenológico na pesquisa. São Paulo: Pioneira Thomson Learning, 2004.

MOREIRA, M. A.; OSTERMANN, F. Sobre o ensino do método científico. Caderno Catarinense de Ensino de Física, v, 10, n. 2, p. 108-117, ago. 1993.

NININ, M. O. G. Pesquisa na escola: que espaço é esse? O do conteúdo ou o do pensamento crítico? Educação em Revista, n. 48, p. 17-35, 2008.

RATHS, L. E. et al. Ensinar a Pensar. São Paulo: EPU, 1977.

RAUSCH, R. B.; SCHROEDER, S. L. A Inserção da Pesquisa nas Séries Iniciais do Ensino Fundamental. Atos de Pesquisa em Educação, v. 5, n. 3, p. 315-337, set./dez. 2010.

ROSA, C. T. W. A metacognição e as atividades experimentais no ensino de Física. 2011, 324 p. Tese (Programa de Pós-Graduação em Educação Científica e Tecnológica) - Universidade Federal de Santa Catarina, UFSC, Florianópolis, 2011. 
ROSA, C. T. W. Instrumento para avaliação do uso de estratégias metacognitivas nas atividades experimentais de Física. Revista Thema, v. 14, n. 2, p. 182-193, 2017.

ROSA, C. T. W. Metacognição no ensino de física: da concepção à aplicação. Passo Fundo: Ed. Universidade de Passo Fundo, 2014.

ROSA, C. T. W.; ROSA, A. B. Ensino de física: A interação social como favorecedora da evocação do pensamento metacognitivo. Revista Espacios, v. 37, n. 24, p. E-2, 2016. Disponível em: <http:// www.revistaespacios.com/a16v37n24/163724e2.html> Acesso em: 28 abr. 2018.

VIANNA, K. Professor de Cientistas: como professores podem transformar seus alunos com a iniciação científica. Cientista Beta, 2016, E-book. Disponível em: <http://giovaninovelli.wixsite. com/meusite>. Acesso em: 03 jul. 2018.

WEKERLIN FILHO, D. O aluno pesquisador: estudo de caso na Escola Ecológico Rincão. 2001. 95 p. Dissertação (Mestrado em Engenharia de Produção) - Universidade Federal de Santa Catarina, Florianópolis, 2011.

ZULIANI, S. R. Q. A; ÂNGELO, A. C. D. A utilização de estratégias metacognitivas por alunos de química experimental: uma avaliação da discussão de projetos e relatórios. In: II ENCONTRO NACIONAL DE PESQUISA EM EDUCAÇÃO EM CIÊNCIAS, Atas... Valinhos, SP, 1999.

\section{NOTAS}

1 Pesquisa financiada pela Coordenação de Aperfeiçoamento de Pessoal de Nível Superior (CAPES).

\section{Submetido em 03/04/2020 \\ Aprovado em 27/11/2020}

\section{Contato:}

Av. Avelino Talini, 171, s. 325/2 - Bairro Universitário

CEP 95.914-014 - Lajeado, RS - Brasil 